Res Publica. Revista de Historia de las Ideas Políticas ISSN: 1576-4184

http://dx.doi.org/10.5209/RPUB.60847

\title{
Lecturas intrincadas: Maquiavelo, Aristóteles, Tomás de Aquino*
}

\author{
Carlo Ginzburg**
}

Recibido: 21 de febrero de 2018 / Aceptado: 15 de junio de 2018

Resumen. La rehabilitación del pensamiento de Nicolás Maquiavelo que intentara Kaspar Schoppe en su Paideia politices, en donde afirmaba que este solo estaba repitiendo argumentos ya planteados por Aristóteles y Tomás de Aquino, nos permite reconocer la intrincada relación entre las diferentes lecturas que dieron lugar a la composición de esta defensa. Una adecuada contextualización de la misma, señalando la correcta distantica entre las perspectivas etic y emic quizás pueda permitirnos conocer mejor el significado del pensamiento maquiaveliano.

Palabras clave: Maquiavelo; Aristóteles; Tomás de Aquino; Scioppius; etic y emic.

\section{[en] Intricate Readings: Machiavelli, Aristotle, Thomas Aquinas}

\begin{abstract}
The rehabilitation of the Machiavelli thought that Kaspar Schopper tried in his Paideia policies where he affirmed that Machiavelli was just repeating arguments that Aristotle and Thomas Aquinas had already stated before, allows us to recognize the intricate relationship among the different readings that give rise to the composition of this defense. An appropriate contextualization of such different readings that pointed the right distance between etic and emic approaches, perhaps could allow us to know better the real meaning of Machiavellian thought.
\end{abstract}

Keywords: Machiavelli; Aristotle; Thomas Aquinas; Scioppius; etic and emic.

Cómo citar: Ginzburg, C. (2018). Lecturas intrincadas: Maquiavelo, Aristóteles, Tomás de Aquino, en Res publica $21.2,215-235$.

\footnotetext{
* Versión revisada del texto de la Nicolai Rubinstein Lecture que, gracias a la invitación de Quentin Skinner, tuve el honor de dictar en la Queen Mary University of London, el 20 de marzo de 2014. Quisiera agradecer los comentarios críticos de Franco Bacchelli, Maria Luisa Catoni y del propio Quentin Skinner; también la ayuda que me prestara en mi investigación a Maria Rosaria Manunta, Directora de la Biblioteca Universitaria de Sassari y finalmente, a los anónimos referees del Journal of the Warburg and Courtauld Institutes por sus comentarios y sugerencias. [Publicado originalmente como: "Intricate Readings: Machiavelli, Aristotle, Thomas Aquinas", Journal of the Warburg and Courtauld Institutes, vol. LXXVIII, 2015, pp. 157-172. Trad. cast. M. Barbuto, atentamente controlada por el autor. Si no se indica lo contrario los textos que aparecen entre corchetes son de la autoria del traductor. Agradezco la valiosa colaboración del profesor Francisco Bertelloni (F.B.), Facultad de Filosofía y Letras, Universidad de Buenos Aires].

** Scuola Normale Superiore, Pisa (Italia) ginzburg@history.ucla.edu
} 
La compleja y enredada relación entre las diferentes lecturas que abordaré a continuación tiene su origen en un breve tratado escrito en latín y publicado en Roma en 1623: Paedia politices, título que traduciré, aplicando un intencional anacronismo que más adelante justificaré, como Fundamentos de la Política. Su autor, Kaspar Schoppe, más conocido en la versión latinizada como Scioppius, había nacido en Baviera en 1576 en el seno de una familia luterana. En su juventud se convirtió al catolicismo y viajó a Roma donde paso varios años bajo la protección de diferentes cardenales y papas. Scioppius era un intelectual militante. Hasta su muerte en 1649 en Padua escribió una gran cantidad de textos atacando a los protestantes, enfrentando a los jesuitas y en contra de Joseph Justus Scaliger (1540-1609), famoso erudito que llegó a ser un declarado archi-enemigo de los jesuitas ${ }^{1}$. En el siglo XIX, su biógrafo, Charles Nisard, incluía a Scioppius entre los "gladiateurs" de la República de las Letras, una definición, por cierto, más que merecida ${ }^{2}$.

En su Paedia politices, que había dedicado al Cardenal Ludovico Ludovisi, Scioppius defendía una causa que no era precisamente muy popular: se proponía rehabilitar a Maquiavelo, cuya obra figuraba en el Index librorum prohibitorum desde $1559^{3}$. En poco menos de cincuenta páginas Scioppius lograba resumir lo esencial de una argumentación que ya había desarrollado en su compleja y extensa Machiavellica, una apología del pensamiento de Maquiavelo que había sido escrita en 1618 y que si bien circulaba en versión manuscrita nunca sería publicada 4 . Pese a que en Paedia politices nunca se mencionaba explícitamente a Maquiavelo, esto no quería decir, por cierto, que el Secretario florentino no se encontrara efectivamente en dicha obra. No es de extrañar entonces, que su nombre apareciera agregado varias veces por una mano del siglo XVII en los márgenes de un ejemplar de la primera edición de Paedia politices que he podido consultar en la Research Library de la UCLA ${ }^{5}$. Dicho brevemente, la posición de Scioppius era la siguiente: las duras críticas que han recibido algunos pensadores políticos (que nunca identificará expresamente), cuyas obras habían sido publicadas bajo el auspicio del papado, eran del todo injustas puesto que

K. Jaitner (ed.), Kaspar Schoppe. Autobiographische Texte und Briefe, Múnich, C.H. Beck, 6 vols., 2004-2012.

C. Nisard, Les gladiateurs de la République des Lettres au XVe, XVIe et XVIIe siècles, 2 vols., París, Michel Lévy Frères, 1860, II, pp. 1-206.

3 Cf. V. Frajese, "Index librorum prohibitorum", en G. Sasso y G. Inglese (eds.), Enciclopedia Machiavelliana [EM.], 3 vols., Roma, Istituto della Enciclopedia italiana Treccani, 2014, II, pp. 12-17.

4 C. Nisard, Les gladiateurs, op. cit., pp. 155-157. M. d'Addio, Il pensiero politico di Gaspare Scioppio e il machiavellismo del Seicento, Milán, Giuffrè, 1962, pp. 383-574 y G. Procacci, Machiavelli nella cultura europea dell'età moderna, Roma y Bari, Laterza, 1995, pp. 158-160. Cf. también, P. Carta "Schoppe (Scioppio), Kaspar", en EM. II, pp. 498-499 y G. Almási "Rehabilitating Machiavelli: Kaspar Schoppe with and against Rome", en History of Europeans Ideas 42, 8, 2016, pp. 981-1004. Continúo desarrollando aquí una interpretación de la obra maquiaveliana que presentara en mis: "Machiavelli, l'eccezione e la regola. Linee di una ricerca in corso", en Quaderni storici, XXXVIII, 112 (1), 2003, pp. 195-213 [trad. cast. M. Barbuto, en Ingenium 4, 2010, pp. 5-28] y „Spuren einer Paradigmengabelung. Machiavelli, Galilei und die Zensur der Gegenreformation”, en, S. Krämer, W. Kogge y G. Grube (eds.), Spur: Spurenlesen als Orientierungstechnik und Wissenskunst, Frankfurt, Suhrkamp, 2007, pp. 257-280.

$5 \quad$ UCLA, Special Collections, Z. 233. A 42. S373. 1623: C. Scioppius, Paedia Politices sive Suppetiae logicae scriptoribus politicis latae adversus AПAIAEVIIAN et acerbitatem plebeiorum quorundam iudiciorum [Caspar

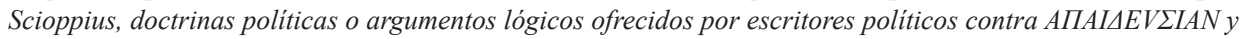
la excesiva severidad de algunos juicios vulgares, Roma, 1623. (Trad. cast. F.B.)]. 
estos autores no habían hecho otra cosa que repetir los argumentos que ya habían expuesto en su momento Aristóteles y Tomás de Aquino.

Antes de pasar a un análisis detallado de la posición de Scioppius, es importante destacar el gran y duradero impacto que esta tuvo. En la voz "Machiavel" del Dictionnaire historique et critique de Pierre Bayle, cuya primera edición es de 1697, encontramos una nota a pie de página en la que se cita a) un extenso pasaje en el que el erudito alemán Hermann Conring (1606-1681) afirma que Maquiavelo había plagiado a Aristóteles, y b) un extenso pasaje en el que el libertin érudit francés Gabriel Naudé (1600-1653) señalaba que Maquiavelo había plagiado a Tomás de Aquino. Ambas citas (aunque para Bayle era especialmente importante la segunda) remitían de alguna manera a la mencionada Paedia politices de Scioppius: Naudé elogiará la obra en sus Considérations politiques sur les coups d'état en 1639, mientras que Conring la republicará con un comentario junto con la Bibliographie politique de Naudé en $1673^{6}$.

\section{II}

En cualquier caso, hasta aquí he seguido un recorrido muy poco original. Los textos que acabo de mencionar han sido repetidamente citados y en más de una ocasión fueron considerados ejemplos palmarios de la siempre polémica recepción de la obra maquiaveliana ${ }^{7}$. Como es evidente, tanto el maquiavelismo como su contraparte, el anti-maquiavelismo, no deben confundirse nunca con la propia obra de Maquiavelo, en la que por cierto lejos están de encontrarse los banales estereotipos, a favor o en contra, que durante tanto tiempo han condicionado los debates sobre la naturaleza de su pensamiento.

Que duda cabe, por cierto, que siempre he defendido la necesidad de formular este tipo de advertencias ${ }^{8}$. Es más, siempre me he mostrado decididamente favorable a la literatura crítica que ha respetado dichas consignas. De hecho, durante mucho tiempo los críticos han intentado volver a ubicar a Maquiavelo en su propio contexto histórico, debido a que solo así era posible leer y analizar su obra evitando que fuera tergiversada. Ahora bien, a pesar de todo esto, y probablemente inspirado por el Old Nick (el sobrenombre elisabetiano del diablo), no puedo resistir la tentación, precisamente, de hacer el papel de abogado del diablo. Y entonces, no puedo dejar de preguntarme: ¿hasta qué punto la inmaculada y límpida distinción entre la recepción y el análisis de un texto es realmente útil para conocer mejor su significado?

\footnotetext{
P. Bayle, Dictionnaire historique et critique, $6^{\mathrm{a}}$ ed., 4 vols., Basel, J. L. Brandmüller, 1741, III, pp. 244-249 (246 n. E). Cf. G. Naudé, Considérations politiques sur les coups d'état, L. Marin y M. O. Perulli (eds.), París, Les Editions de Paris, 1988, p. 92 [G. Naudé. Consideraciones politicas sobre los golpes de Estado, est. prel., trad. y notas de C. Gómez Rodríguez, Madrid, Tecnos, 1998, p. 92]; ibidem, Bibliographia politica, et Casparis Scioppii Paedia politices ut et ejusdem argumenti alia, [Bibliografia politica, y doctrinas políticas de Caspar Scioppius como también otros textos del mismo tema. (Trad. F.B.)] H. Conring (ed.), Frankfurt, 1673.

7 Será suficiente con recordar el título del extenso estudio de Mario d'Addio sobre Scioppius que citáramos antes aquí en la n. 4.

8 Q. Skinner, "Meaning and Understanding in the History of Ideas", en Vision of Politics, I, Regarding Method, Cambridge, CUP, 2002, pp. 57-89 (publicado por primera vez en History and Theory, VIII, 1969, pp. 3-53). [Trad. cast. H. Pons, en Prismas, 4, 2000, pp. 149-191].

$9 \quad$ Aunque pudiera parecer que con esta pregunta se vuelve parcialmente a algunas de las cuestiones que planteara
} 
Me gustaría dejar bien en claro antes de continuar que soy un decidido crítico (y por cierto desde hace muchos años) de las perspectivas críticas neo-escépticas que afirman que todas las interpretaciones son igualmente válidas. Sin embargo, tampoco estoy de acuerdo con aquellas interpretaciones de la teoría de la recepción que se concentran en la historia de las diferentes lecturas de un determinado texto, como una alternativa, sea implícita o explícita, a la reconstrucción de su significado. Si bien es cierto que la recepción de una obra de arte (o de una novela o de un tratado filosófico) es un objeto de estudio que evidentemente no debe menospreciarse, también es cierto que en ningún caso puede concebirse como una alternativa a la filología: de hecho, creo que hay dos maneras en las que ambas perspectivas críticas pueden llegar a complementarse adecuadamente. Por un lado, como ya he señalado en otro lugar, pueden relacionarse positivamente desarrollando (y reelaborando) la muy conocida distinción, propuesta por el antropólogo Kenneth Pike, entre las perspectivas críticas etic y emic: los historiadores comienzan sus investigaciones formulando preguntas -sus preguntas-inevitablemente planteadas, por lo tanto, en el anacrónico lenguaje del observador. Luego, las respuestas a dichas preguntas, que precisamente tienen como objetivo recuperar el pensamiento de los protagonistas de la historia, a su vez estarán, inevitablemente, elaboradas en un lenguaje que será muy diferente al de los propios historiadores ${ }^{10}$. Traducido al lenguaje de la teoría de la recepción podríamos decir que la dimensión etic haría referencia a los lectores, mientras que la dimensión emic correspondería al texto y a su significado. Y es aquí entonces donde aparece el segundo modo fundamental en que pueden complementarse ambas perspectivas y que quisiera proponer ahora: si las situáramos adecuadamente en el contexto histórico en el que se produjeron, las diferentes lecturas que ha recibido un determinado texto podrían sernos de suma utilidad para intentar acercarnos al significado original de dicho texto. Al proponer esta línea crítica, estoy siguiendo el ejemplo del gran historiador del arte Roberto Longhi (1890-1970), quien de forma admirable demostrara cómo el connoisseur a la hora de analizar una determinada pintura debía realizar un análisis histórico minucioso de la recepción de dicha obra ${ }^{11}$.

Es posible que todo esto suene demasiado teórico, demasiado abstracto. Dejadme retomar, pues, el caso que había comenzado a examinar al inicio del presente texto.

\section{III}

Como hemos visto, en su Dictionnaire, Bayle recogía dos acusaciones distintas que se habían formulado contra Maquiavelo: que había plagiado a Aristóteles y que ha-

Claude Lefort en Le travail de l'oeuvre. Machiavel (Paris, Gallimard, 1972), mi posición, como se verá a continuación, es completamente diferente.

10 Cf. K. L. Pike, Language in Relation to a Unified Theory of the Structure of Human Behavior, La Haya-París, Mouton \& Cia, $2^{\mathrm{a}}$ ed., 1967, pp. 37-72. C. Ginzburg, "Our Words, and Theirs: A Reflection on the Historian's Craft, Today”, en S. Fellman y M. Rahikainen (eds.), Historical Knowledge. In Quest of Theory, Method and Evidence, Cambridge, CUP, 2012, pp. 97-119.

11 R. Longhi, "Due dipinti inediti di Giovan Gerolamo Savoldo" [1927], en Saggi e ricerche: 1925-1928, 2 vols., Florencia, Sansoni, 1967, I, pp. 148-155. La perspectiva crítica que aquí propongo es, por tanto, diferente de la aquellos críticos que han hecho hincapié exclusivamente en la recepción de las obras de Maquiavelo, particularmente por ejemplo en los casos de Procacci (Machiavelli nella cultura, op. cit.,) y de S. Anglo, Machiavelli. The First Century: Studies in Enthusiasm, Hostility, and Irrelevance, Oxford, OUP, 2005. 
bía plagiado a Tomás de Aquino. Ambas acusaciones nos permitían volver (aunque presentadas en orden inverso) al pensamiento de Scioppius, quien en su Paedia politices había afirmado, si bien como un elogio antes que como una crítica, que los siniestros argumentos que les habían sido adjudicados a algunos, nunca identificados, "pensadores políticos" - es decir, a Maquiavelo- ya habían sido formulados con anterioridad por Aristóteles y por Tomás de Aquino. Mi propósito en este texto, por lo tanto, es examinar la posibilidad de que la interpretación de Scioppius, sin dejar de tener en cuenta su estrecha relación con el contexto de la Roma de la Contrarreforma, pueda ayudarnos de alguna manera a comprender mejor la obra de Maquiavelo, una obra que había sido escrita en Florencia 100 años antes. Dicho de otro modo, me propongo evaluar la posibilidad de que la interpretación históricamente contextualizada de Scioppius pueda constituir una referencia crítica que a su vez pueda sernos de utilidad para formular nuestra propia interpretación. (Posibilidad, claro está, que también podría contemplarse ante la misma interpretación que aquí estoy presentando).

Podríamos comenzar haciéndonos la siguiente pregunta: ¿había leído Maquiavelo la Política de Aristóteles? Dado que Aristóteles es explícitamente mencionado en los Discorsi sopra la prima deca di Tito Livio, [Discorsi] III, 26, 10 ${ }^{12}$, parecería del todo evidente que la respuesta es afirmativa. Es más, aunque en este caso la cuestión es algo más discutible, encontramos alguna evidencia también en el intercambio epistolar con Francesco Vettori de finales de agosto de 1513, cuando, en la carta del 20 de agosto, Vettori hace referencia a Aristóteles. Después de haber señalado que la expansión de los suizos tenía algunas limitaciones intrínsecas, Vettori respaldaba su análisis citando a una autoridad en la materia:

perché, se voi leggerete bene la Politica, et le republiche che sono state, non troverrete che una republica, come quella, divulsa, possa fare progresso.

[puesto que si lees con atención en la Política todas las clases de repúblicas que han existido en el pasado, te darás cuenta que una república fragmentada, como lo es esta [Suiza], no puede expandirse con éxito] ${ }^{13}$.

El 26 de agosto, como se recordará, Maquiavelo responde con cierto fastidio:

Né so quello si dica Aristotile delle republiche divulse; ma io penso bene quello che ragionevolmente potrebbe essere, quello che è, et quello che è stato.

[Pues la verdad no sé qué es lo que dice Aristóteles sobre las repúblicas fragmentadas. A mí en realidad lo que me interesa es lo que lógicamente podría suceder, lo que está pasando ahora y aquello que ya ha sucedido] ${ }^{14}$.

Con su airada respuesta Maquiavelo estaba reaccionando contra una perspectiva crítica que basaba el análisis de la realidad política en la autoridad de los textos ca-

12 N. Machiavelli, Discorsi, (Edizione Nazionale delle opere di N.M. [ENO]), F. Bausi (ed.), 2 vols., Roma, Salerno Editrice, 2001, II, p. 694.

13 Carta de Vettori a Maquiavelo del 20 de agosto de 1513, en N. Machiavelli, Opere, C. Vivanti (ed.), 3 vols., Torino, Einaudi, 1997-2005, II, p. 285. Cf. Mario Martelli, "Detalles de la filología", (trad. cast. M. B.), Ingenium 11, 2017, pp. 239-306, aquí p. 242 n. 17]

14 Carta de Maquiavelo a Vettori del 26 de agosto de 1513, ibidem., p. 289, y p. 1567. Cf. Martelli, "Detalles", p. 276 n. 101. 
nónicos. Tiempo después, como es sabido, en los Discorsi, II, 4, 23-24, Maquiavelo terminará aceptando implícitamente la posición de Vettori acerca de las limitaciones intrínsecas de la expansión territorial de los suizos ${ }^{15}$. Aquí lo que me interesa destacar, con todo, es que Vettori no necesitaba mencionar explícitamente a Aristóteles, precisamente porque daba por sentado que Maquiavelo conocía muy bien el texto del Estagirita ${ }^{16}$. Unos meses más tarde, el 13 de diciembre, Maquiavelo comunicará a Vettori que estaba componiendo Il principe:

io ho [...] composto uno opuscolo De principatibus; dove io mi profondo quanto io posso nelle cogitationi di questo subietto, disputando che cosa è principato, di quale spetie sono, come e'si acquistono, come e'si mantengono, perchè e`si perdono.

[...y he compuesto el opúsculo de principatibus, donde desarrollo con toda la precisión de la que soy capaz este tema, exponiendo qué es un principado, de cuántas clases son, cómo se instauran, cómo se mantienen y por qué motivos se pierden] ${ }^{17}$.

De hecho, este sumario de los primeros once capítulos de Il principe recuerda (como ya fuera señalado) el elenco de temas que aparecen en la Política de Aristóteles ${ }^{18}$. No es mi intención, por cierto, hacer de Maquiavelo un pensador aristotélico, cosa que, evidentemente, no era ${ }^{19}$. Es más, en términos generales, podría afirmarse que Maquiavelo no era precisamente un "erudito". Sin embargo, en la dedicatoria de Il principe sostiene que él conoce las acciones de los grandes hombres de la historia, gracias a una "gran experiencia en la política contemporánea y a una constante lectura de los eventos políticos de la antigüedad" ${ }^{20}$. Lecturas que sin duda alguna incluirían la Política de Aristóteles, pero entonces deberíamos preguntarnos: ¿cuál era la edición que había leído Maquiavelo?

15 N. Machiavelli, Discorsi, op. cit., p. 333.

16 Conocimiento que Mario Martelli negara en "Machiavelli e i classici”, en Cultura e scrittura di Machiavelli. Atti del Convegno di Firenze-Pisa 27-30 ottobre 1997, Roma 1998, pp. 279-309, esp. pp. 291-292; M.Martelli, "I dettagli della filologia" en ID., Tra filologia e storia. Otto studi machiavelliani, Roma, Salerno editrice, 2009, pp. 306-309 (publicado originalmente en Interpres XX, 2001, [2003], pp. 212-71, y finalmente, su comentario a Principe, XVIII, 13 en N. Machiavelli. Il principe, M. Martelli (ed.), aparato filológico N. Marcelli, Roma, Salerno editrice, 2006, n. 26 y 27 pp. 239-240). Los argumentos aquí expuestos, a mi entender, permitirían demostrar todo lo contrario.

17 N. Machiavelli, Opere, op. cit., II, p. 296. [Cf. W. Connell, "La carta de Maquiavelo a Vettori del 10 de diciembre de 1513”, en M.Barbuto. (ed.), Problematizing Il principe, Barcelona, Edicions de la Universitat de Barcelona, 2017, pp. 11-91, aquí, p. 61 y 72]

18 La gran diferencia que habría entre estos capítulos de $I l$ principe y los siguientes fue señalada en su momento por Friedrich Meinecke en un controvertido artículo: cf. su introducción a N. Machiavelli, Der Fürst und kleinere Schriften, Berlin, R. Hobbing, 1923, pp. 38-47. [Cf. N. Machiavelli, Il principe, G. Inglese (ed.), Turín, Einaudi, 2013, p. xxi n. 31].

19 Para un esquema de la relación de la obra maquiaveliana con la obra de Aristóteles, cf. P. Falzone, "Aristotele", en E.M. I, pp. 94-100, quien no ha tenido en cuenta las etapas anteriores de la investigación que ahora aquí se desarrolla. Cf. A. M. Cabrini, "Principe e tiranno in Machiavelli”, en Ragionare dello stato: Studi su Machiavelli, Milán, Ledizioni, 2017, p. 64 n. 65.

20 N. Machiavelli, Il Principe: "una lunga esperienza delle cose moderne e una continua lezione delle antiche". Cf. F. Bausi, Maquiavelo, trad. cast. M. Barbuto., Valencia, PUV, 2015, p. 209 y N. Machiavelli, El príncipe / De principatibus, ed. bilingüe con texto italiano de G. Inglese, est. prel. y notas de H. Puigdoménech, Madrid, Tecnos, 2011, p. 5. 


\section{IV}

El segundo paso que propongo llevar a cabo en el presente análisis es sin duda mucho menos obvio que el anterior. A menudo el debate crítico a cerca de las fuentes del pensamiento de Maquiavelo se ha basado en textos cuyas ediciones él nunca pudo haber conocido, incluso en ocasiones, en textos escritos en lenguas (como por ejemplo, el griego) que Maquiavelo no era capaz de leer ${ }^{21}$. Según creo, podemos remediar estas anacrónicas distorsiones limitando nuestra búsqueda a las siguientes tres fuentes ${ }^{22}$ :

(1) las obras de Aristóteles (incluyendo la Política) con comentarios de Averroes que fueran impresas en tres volúmenes en Venecia en 1483;

(2) Le livre de politiques d'Aristote, traducción francesa de Nicolás Oresme, impresa en París en 1489, y

(3) la traducción latina de la Política comentada por Tomás de Aquino de Leonardo Bruni que fuera publicada en Roma en 1492.

En mi opinión es esta última (o probablemente su reimpresión, publicada en Venecia en 1500), la edición que habría leído Maquiavelo ${ }^{23}$. Hipótesis que de verse confirmada daría lugar a una serie de cajas chinas que propongo ir abriendo a continuación siguiendo un orden cronológico inverso:

- la doble acusación formulada contra Maquiavelo de haber plagiado tanto a Aristóteles como a Tomás de Aquino, sería una tergiversación de

- la posición de Scioppius, en la que Maquiavelo aparecía implícitamente definido como un seguidor tanto de Aristóteles como de Aquino, que a su vez sería una descripción un tanto apresurada del

21 Por ejemplo, en un reciente texto sobre los Discorsi, todas las citas de la Política de Aristóteles han sido tomadas de la traducción de L. Bruni (G. Pedullà, Machiavelli in tumulto. Conquista, cittadinanza e conflitto nei Discorsi sulla prima deca di Tito Livio, Roma, Bulzoni, 2011, p. 22 n. 22 y passim, donde se reenvía a Aristotele, Politicorum libri, a cura di Raffaele Volterrano, traduzione di Leonardo Bruni, Venezia, Hiernonymus Scotus, 1542), texto que fuera publicado en Venecia 15 años después de la muerte de Maquiavelo. En realidad, por otra parte, Raffaele Maffei, conocido como "il Volterrano" (1451-1552), no había sido el editor de la obra sino el autor de los breves résumés que servirían de introducción a cada libro. La referencia correcta sería entonces: Aristotle Stagiritae Politicorum ad Nicomachum lib. primus Raphaelis Volaterrani argumenta in eosdem. Leonardo Bruni interprete, [Interpretaciones de Raffaele Volterrano sobre el libro I de la Política del Estagirita Aristóteles a Nicómaco, traducido por Leonardo Bruni. (Trad. F.B.)] Venecia (Hieronymus Scotus), 1542 [=1543].

22 Para estas fuentes he utilizado el fundamental elenco bibliográfico sobre Aristóteles que aparece en el apéndice de N. M., The Discourses, trad. y ed. L. J. Walker, 2 vols., New Haven, CT, 1950, II, pp. 273-77.

23 Para la edición de Roma de 1492 cf. el quinto punto del presente texto y la n. 28. La reimpresión es Thomas Aquinas, In octo Politicorum Aristotelis libros cum textu eiusdem. Interprete Leonardo Aretino, [comentario a los ocho libros de la Política de Aristóteles, con texto de Aristóteles, comentados por Leonardo Aretino. (Trad. F.B.)] Venecia 1500 (colofón: "Venetiis, impensis domini Andree Torresani de Asula arte vero Simonis de Luere ultimo mensis Octobris MD. Feliciter" [Impreso con éxito en Venecia a expensas del señor Andrea Torresani de Asula por Simón de Luere el mes de octubre de MD. (Trad. F.B.)] UCLA, Special Collections, *A1. T36i.1500 [reverso], Ahmanson Murphy Aldine Collection. En Venecia en 1514 fue publicada otra edición, "mandato et impensis heredum...Octaviani Scoti ciuis Modoetiensis et sotiorum summa diligentia impressis Venetijs per Georgium Arrivabenum" [impreso con sumo cuidado en Venecia por Jorge Arrivabenum por encargo y a expensas de los herederos... de Octaviano Scoto ciudadano de Monza y asociados. (Trad. F.B.)]; se puede encontrar un ejemplar en la Biblioteca Nazionale Centrale de Florencia, MAGL. 5.2.338./b. Para estas y otras ediciones relacionadas con las mencionadas véase, el todavía fundamental artículo de C. Martin, "The Vulgate Text of Aquinas's Commentary on Aristotle's Politics”, en Dominican Studies V, 1952, pp. 35-64. 
- decisivo impacto que supusiera para Maquiavelo la lectura de la Política de Aristóteles comentada por Tomás de Aquino. (Hasta donde sé, sólo una temprana edición, publicada en 1478 en Barcelona, advierte que la segunda parte del comentario fue escrita por un discípulo "e imitador" de Tomás de Aquino, Pedro de Alvernia) ${ }^{24}$.

Bien es verdad, que la posibilidad de que Maquiavelo hubiera leído la Política de Aristóteles junto con el comentario de Tomás de Aquino fue sugerida hace tiempo, especialmente por Leslie J. Walker. Sin embargo, al presentar a Tomás de Aquino como fuente del pensamiento de Maquiavelo, Walker hacía hincapié fundamentalmente en el De regimine principum. Aquí, por el contrario, propongo concentrar nuestro análisis tanto en la Política de Aristóteles, y particularmente en el quinto libro, como en el comentario atribuido a Tomás de Aquino (que en realidad, como acabamos de mencionar, había sido escrito por su discípulo $)^{25}$.

Pero antes de continuar considero necesario presentar una descripción del libro que probablemente leyera Maquiavelo. Es un volumen en folio, impreso en Roma por Eucharius Silber alias Franck en 1492, que presenta en cada página junto al texto de Aristóteles el comentario de Tomás de Aquino ${ }^{26}$. El ejemplar que he consulta-

24 L. Lanza, "Aspetti della ricezione della Politica aristotelica nel XIII secolo: Pietro di Alvernia", en Studi Medievali ser. III, XXXV, 1994, pp. 643-694. Cf. Thomas Aquinas, In libros polithicorum Ar[istotelis] comentum foeliciter incipit, Barcelona, 1478, colofón: "Comentum in Ar[istotelis] polythicorum libros per sanctum Thomam fratrem ordinis predicatorum initum per venerabilem vero Petrum Alverniensem eiusdem ordinis fratrem illius doctrine studiosum ac solertem imitatorem. Absolutum foeliciter explicit ab Ioanne Ferrario cive barchin[onensi] humanitatis studiorum amantissimo accuratissime emendatum qui ut legentibus Ar[istotelis] commemoratos polythicorum libros facilitor sit aditus textui antiquae traductionis huius nove Leonardi Arethini textum subiungere non pretermisit... Petro Bruno et Nicholao Spindeler ... qui... impressionem apud Barchinonam urbem absolverunt, XVIIII mensis Decembris 1478". [Comentario a los libros políticos de Aristóteles realizado por Santo Tomás, fraile de la orden de los predicadores, y concluído por Pedro de Alvernia de la misma orden seguidor e imitador de su doctrina. Terminado y cuidadosamente corregido por Juan Ferrario ciudadano de Barcelona amante del estudio de las humanidades, quien, para que los mencionados libros de Aristóteles sean más accesibles a los lectores de Aristóteles, no omitió agregar al texto de la antigua traducción esta nueva de Leonardo Aretino para que Pedro Bruno y Nicolás Spindeler llevaran a cabo la impresión en la ciudad de Barcelona el 18 de diciembre de 1478. (Trad. F.B.)]. [http://mdc.cbuc.cat/cdm/compoundobject/collection/incunableBC/ id/20044/rec/1] He utilizado una reproducción del ejemplar que se encuentra en la Biblioteca Universitaria de Sassari. No he podido consultar en cambio, Aristotle, Politicorum libri, trad. Leonardo Bruni, Barcelona (N. Spindeler) 1481; obra de la que hay una copia en el convento de San Francisco de Asís de Barcelona.

25 L. J. Walker, II, pp. 293-298, esp. 298, quien en cualquier caso hace alguna referencia menor, sin llegar a presentar un verdadero comentario, al quinto libro de la Política. Vale la pena recordar que, si bien de un modo un tanto paradojal, la posibilidad de que Maquiavelo hubiera leído la Summa de Tomás de Aquino ya había sido sugerida por C. Singleton ("The Perspective of Art", en The Kenyon Review XV, 2, 1953, pp. 169-189, esp. 188). Como prueba de la gran influencia que ha tenido en mi interpretación de la obra maquiaveliana el artículo de Singleton, véase, mi "Machiavelli, l'eccezione e la regola", op. cit., pp. 204-205. [La relación entre el pensamiento de Tomás de Aquino y el de Maquiavelo ha sido muy pocas veces analizada con el suficiente detenimiento por la crítica (cf. por ejemplo, Daniel M. Nelson, The Priority of prudence: virtue and natural law in Thomas Aquinas and the implications for modern ethics, Pennsylvania, The Pennsylvania State University Press, 1992): significativamente, en la reciente E.M, no se ha incluido la voz respectiva].

26 Th. Aquinas, Commentaria ... in octo Politicorum Aristotelis libros cum textu eiusdem. Interprete Leonardo 
do en la Biblioteca Comunale degli Intronati de Siena es especialmente importante puesto que originalmente pertenecía a quien fuera el impulsor del proyecto editorial: Agostino Piccolomini (1470-1496), sobrino del Cardenal Francesco Tedeschini Piccolomini ${ }^{27}$. En la dedicatoria dirigida a Lodovico da Valenza, un erudito frayle dominico y profesor de teología, que había sido su maestro, Agostino relata cómo durante el verano anterior, encontrándose en la Toscana, había llegado a sus manos un manuscrito del comentario de Tomás de Aquino de la obra de Aristóteles. La idea de Agostino de publicar el comentario sufriría una importante demora debido a que el manuscrito, copiado por una mano incompetente, estaba repleto de errores y de comentarios carente del más mínimo sentido. Habiendo buscado sin éxito en Roma otros manuscritos para poder compararlos con el que había encontrado, Agostino terminará encargando el proyecto editorial al fraile Lodovico, "para de esa manera ayudar a todos aquellos hombres comprometidos con los asuntos públicos (civiles viri), que se esfuerzan denodadamente en comprender la obra de Aristóteles". Una edición corregida, impoluta, afirmaba Agostino, tendría un valor incalculable para quienes "gobiernan ciudades y administran Estados", porque "cada vez que necesitan leer a Aristóteles para poner en práctica sus preceptos se ven obligados a enfrentarse con diferentes interpretaciones de sus palabras" hecho que, finalmente, provoca "que terminen rechazando e ignorando a Aristóteles". Sin embargo, si el fraile Lodovico aceptaba llevar a cabo esta empresa editorial "ellos te alabarían, pues serían capaces de poner en práctica los preceptos de Aristóteles, y entonces así lo venerarían". "Tú deberías dejar por un tiempo tus estudios sobre teología" -insistía Agostino- "y dedicarte únicamente a revisar y corregir estos comentarios, limpiándolos como si estuvieras podando las plantas de un huerto". "Deberías tener en cuenta, también, la traducción de la Política de Aristóteles de Leonardo Bruni, aunque" -y Agostino hace un decidido hincapié en este aspecto- "ha sido publicada de tal manera que de Bruni no ha sobrevivido ni una palabra" 28 . Por lo tanto, "gracias al resultado de tu trabajo se podrá conocer a un Aristóteles sin defecto alguno" y de esa manera "será posible que Tomás de Aquino, condenado en el pasado a la oscuridad, recupere todo su esplendor"29.

Arentino, Roma, 1492. En el colofón se puede leer: “impressum est hoc opus Romae per magistrum Eucharium Silber alias Franck, xiiii kal. Aug. 1492". Para esta edición (IGI 841; ISTC ia01024000) cf. Martin, “The Vulgate", op. cit., pp. 41-43 (cabe destacar, por cierto, que la mención a la crítica de Lodovico da Valenza es algo superficial).

27 Biblioteca Comunale degli Intronati, a-z8 A-18. Es importante no confundir a este Agostino Piccolomini con Agostino Patrizi Piccolomini [Cf. N. Mahmoud Helmy, "Patrizi Piccolomini, Agostino", en Dizionario biografico degli italiani 81, 2014]. Cf. R. Avesani, "Per la biblioteca di Agostino Patrizi Piccolomini vescovo di Pienza”, en Mélanges Eugène Tisserant, 7 vols., Ciudad del Vaticano, Biblioteca Apostólica Vaticana, 1964, VI (Bibliothèque Vaticane, I), p. 2 n. 4.

28 Probablemente esta sea una referencia a la edición publicada en Barcelona en 1478. Otra posibilidad sería que hiciera referencia a: Aristoteles, Ethica, Politica et Oeconomica, Leonardo Bruni interprete, Strasbourg (Johann Mentelin) ante 10 de abril de 1469. Cf. K. Schorbach, Der Strassburger Frühdrucker Johann Mentelin (14581478). Studien zu seinem Leben und Werke, Mainz, Gutenberg-Gesellschaf, 1932, Apéndice, p. 10.

29 Th. Aquinas, Commentaria, 1492 (aquí n. 23), sig. a1v: "Quod si (ut spero) expolitum candidumve librum praestabis, quantam ab his qui civitatibus praesunt qui ve una respublicas administrant sis consecuturus tu qui prudentissimus es considera. Hi enim cum Aristotelem legunt ut praecepta solum exequantur, dum in verborum interpretatione immorari eos necesse est et Aristotelem damnant et negligunt. Quod si laborem hunc dempseris et summopere te laudabunt et philosophi praecepta exequentes Aristotelem maxime venerabuntur. Quare te rogo ut omissis paulum sacris studiis, ad hos commentarios corrigendos emendandosque tanquam in hortulum, cum tibi per maximas curas licebit, descendas, ut si forte eos Leonardi Aretini translationi, quae ita confuse impressa 
A esta le sigue otra dedicatoria, del editor, el fraile Lodovico, al cardenal, tío de Agostino, quien, una década más tarde llegaría a ser, si bien por pocos meses, el papa Pío III (Francesco Piccolomini era sobrino del papa Pío II, Enea Silvio Piccolomini). Como podemos ver, estos nombres hablan por sí solos: el proyecto editorial de publicar el comentario de la Política de Aristóteles de Tomás de Aquino había sido concebido en Siena en un ambiente humanista al más alto nivel de la jerarquía eclesiástica. El comentario de Tomás de Aquino era concebido por tanto como una herramienta indispensable para poner en práctica los preceptos de Aristóteles. Sin embargo, como advirtiera Lodovico, aún quedaba un problema por resolver: él no estaba dispuesto a aceptar la postura de quienes pensaban que la vieja traducción comentada por Tomás de Aquino (era el caso de la famosa versión de la Política de Aristóteles de William de Moerbeke) no era fiel al texto aristotélico ${ }^{30}$. Sin embargo, al mismo tiempo, era evidente que la traducción de Bruni era "más cristalina" y su latín "más correcto". Por lo tanto, Lodovico llegó a la conclusión de que "si bien Santo Tomás había comentado una vieja traducción, al hacerlo parecía estar interpretando la nueva"31. Y de esa manera, entonces, el problema quedaba resuelto.

Textos renovados, más fidedignos, escritos en un mejor latín, textos, por lo tanto, concebidos como instrumentos necesarios para mejorar el ejercicio de la política: precisamente eso era lo que podía esperarse de una edición renacentista de Aristóte-

est, ut ne verbum quidem Aretini contineat, adnectere velimus, possumus uno tempore Aristotelem mendis vacuum, Divumque Thomam in tenebris latitantem in lucem emitter". [Tú, prudentísimo, considera que si, como espero, presentas un libro bien redactado y estructurado, recibirás una gran gratificación de quienes gobiernan las ciudades y de los que administran las repúblicas. Pues es necesario censurar a quienes leen a Aristóteles solo porque deben leerlo pues con la interpretación que hacen de sus palabras ofenden y tergiversan su obra. Si haces este trabajo con cuidado los filósofos te honrarán y entonces sí los preceptos aristotélicos serán venerados. Por ello te ruego que abandones por un tiempo tus estudios religiosos, y comiences a dedicarte solo a estos comentarios que deben ser corregidos y enmendados de la misma manera que se poda un huerto, pues la traducción de Leonardo Aretino se publicó de manera tan confusa que no contiene ni una palabra que le pertenezca. Tu edición debe ofrecer un Aristóteles sin errores que pueda sacar a Tomás de Aquino de la oscuridad en la que encuentra sumergido para devolverle así todo su esplendor. (Trad. F.B.)].

30 Aristotle, Politicorum libri octo cum vetusta translatione Guilelmi de Moerbeka [Ocho libros de la Política con la vieja traducción de Guillermo de Moerbecke. (Trad. F.B.)], F. Susemihl (ed.), Leipzig, 1872.

31 Th. Aquinas, Commentaria, 1492, sig. a2r: "Sed cum Leonardi Aretini translatio aperta magis et latina sit, que tamen impressa nec Aretini verbum continere videatur, suasit et Thomae interpretationem ei coaptare translationi et expurgare depravatum Aristotelis librum. Hoc certe satis mihi difficile visum est, eos recte sentire existimans, qui veterem translationem, quam tamen Thomas commentatus fuit, non consentiri Aristoteli censent. Verum experimento didici eiusmodi viros quod non intelligant temere iudicare. Nihil enim magis consonum et consentaneum et coaptatum esse potest quam vetus novaque Politicorum Aristotelis translatio. Nam etsi Divus Thomas veterem exposuerit, novam tamen interpretari videtur" [Pero, puesto que la traducción latina de Leonardo Aretino es más clara y no parece contener ninguna expresión de Aretino, aconsejo agregar a esa traducción el comentario de Tomás y expurgar así el libro corrompido de Aristóteles. La verdad me parece difícil concebir que ellos puedan llegar a considerar que la vieja traducción que había comentado Tomás no coincide con Aristóteles. Realmente he aprendido por experiencia que los hombres ignorantes no deben opinar; puesto que nada puede ser más adecuado y correcto que la vieja y la nueva traducción de la Política de Aristóteles. Pues aunque Tomás comentara la antigua traducción, parece como si hubiera interpretado la nueva. (Trad. F.B.)]. Sobre este tema véase, F. E. Cranz, "The Publishing History of the Aristotle Commentaries of Thomas Aquinas", en Traditio XXXIV, 1978, pp. 157-192, aquí 171-172. 
les. Sin embargo, la yuxtaposición de la traducción de Bruni del texto de Aristóteles y del comentario de Tomás de Aquino - un palacio de la antigüedad, encorsetado por un edificio medieval, presentado y explicado por un humanista- generaba, sin duda, una tensión latente.

Tensión que bien podía reconocerse en la dedicatoria de Agostino Piccolomini al fraile Lodovico, en donde, de un modo del todo concluyente, se afirmaba que: el "horrible y sucio" (horridum immundumque) manuscrito en el que se basaba esta edición debía ser completamente purgado. No debían aceptarse ninguno de los agregados ni de las omisiones que hubiera realizado el copista. Debía eliminarse del texto todo aquello que fuera burdo, inculto o bárbaro ${ }^{32}$. La firme convicción de la intrínseca convergencia entre la verdad y el latín clásico favorecían el rechazo (algo con lo que no estaba tan de acuerdo, como hemos visto, el editor, el fraile Lodovico) de la vieja traducción comentada por Tomás de Aquino. Pero entonces: ¿en qué situación quedaba el comentario de Tomás de Aquino? ¿Debía ser considerado también "inculto" y "bárbaro"?

Es posible que no sea tan evidente el sentido que tiene el haber recordado estas agrias polémicas. Quizás hayan inspirado un pasaje de la dedicatoria de Lodovico da Valenza en el que ataca "a aquellos oradores de nuestro tiempo que desprecian a todos los escritores que no tengan en cuenta la historia o que no polemicen con la retórica; que se niegan a leer y a conocer a cualquiera que no haga esto"33. Inmediatamente después de esta polémica afirmación, Lodovico se defendía, por un lado, dejando bien en claro su veneración por Platón, Teofrasto y sus traductores, como por ejemplo, Teodoro Gaza, y por otro, desplegando un nuevo ataque, esta vez contra:

Sed in illos dico qui totius naturae ignari cum aliquid de Urbe condita [de Livio] aut de Rhetoris officio possunt dicere omnium se artium censores faciant ${ }^{34}$.

[aquellos que no sabiendo nada de la naturaleza, apenas ven que pueden decir algo del de urbe condita o acerca del oficio del orador, se transforman en críticos de todas las demás disciplinas].

¿Quiénes eran estos adversarios de Lodovico (que por cierto nunca serían explícitamente identificados)? Los humanistas, sin duda $^{35}$. Sus vehementes palabras recordaban el carácter polémico que había caracterizado al propio Renacimiento, entendido como un movimiento y no como período histórico, siguiendo la fundamental distinción que propusiera Ernst Gombrich ${ }^{36}$.

32 Th. Aquinas, Commentaria, 1492, fol. 1v: “...ne quid in eo quod a scriptore additum diminutumve sit, inconcinnum, barbarum incultumque legatur" [para que aquello que fue agregado o quitado por el copista no sea leído de modo inculto, bárbaro o burdo. (Trad. F. B.)].

33 Ibidem, fol. 2r: "sed culpa vestra est o Rhetores nostrae aetatis qui contemnitis omnes scriptores qui vel historiam non tradunt vel de oratoria non disserunt. Omnes alios legere et scire recusatis" [pues la culpa es vuestra, oh! Oradores de nuestro tiempo, que despreciais a todos los escritores que no se ocupan ni de historia ni retórica. Os negáis a leer otra cosa. (Trad. F.B.)].

34 Ibidem.

35 Cf. A. Campana, "The Origin of the Word Humanist", en Journal of the Warburg and Courtauld Institutes IX, 1946, pp. 60-73, reimpr. En R. Avesani, M. Feo y E. Pruccoli (eds.), Scritti, I, Ricerche medievali e umanistiche, Roma, Edizioni di storia e letteratura, 2008, pp. 263-281.

36 E. H. Gombrich, “The Renaissance: Period or Movement?", en Background of the English Renaissance: Introductory Lectures, J. B. Trapp (ed.), Londres, Gray-Mills, 1974, pp. 9-30. 


\section{VII}

Durante mucho tiempo se ha concebido a Maquiavelo como sinónimo del Renacimiento (o de la Modernidad, una categoría emic carente, por cierto, de todo valor analítico). Sin embargo, la dicotomía Medioevo/Renacimiento no nos es útil para entender el desarrollo intelectual de Maquiavelo. Como señalé ya hace algunos años, cuando presentaba los primeros resultados del proyecto de investigación que ahora desarrollo aquí, las referencias en el pensamiento de Maquiavelo a las normas y a las excepciones, tanto en la Mandragola como en Il principe, eran el resultado de la lectura de las Quaestiones mercuriales del profesor en derecho canónico Giovanni d'Andrea (c. 1270 - Bolonia, 1348); obra de la que precisamente, Bernardo Maquiavelo, padre de Nicolás, poseía una ejemplar ${ }^{37}$.

Ahora bien, el comentario de la Política de Aristóteles que iniciara Tomás de Aquino y que completara Pedro de Alvernia suponía para Maquiavelo enfrentarse a una cuestión muy diferente: la compleja relación entre la tradición escolástica y el legado de la antigüedad. Si bien no podemos asegurar que Maquiavelo haya leído dicho comentario, sí podemos, en cambio, realizar un experimento: supongamos que sí lo leyó, y entonces, ¿cuál habría sido su reacción si hubiera leído una parte de dicho comentario, particularmente aquella que hace referencia al libro V?

\section{VIII}

Aristóteles afirmaba que la tiranía era "una combinación de las formas extremas de oligarquía y de democracia; es en suma la más perjudicial para los gobernados, por estar compuesta de dos regímenes malos y contener en sí misma las desviaciones y errores de ambos regímenes" ${ }^{\prime 3}$. Luego, pasaba a la cuestión de los modos en los que podía evitarse la caída de los regímenes tiránicos. Cito a continuación el pasaje 1313b4-1313b6 en una traducción moderna de la Política:

Las tiranías se pueden mantener de dos maneras totalmente opuestas. Una es la más tradicional, y es según la cual gobierna la mayoría de los tiranos. Se dice que muchos de estos procedimientos fueron establecidos por Periandro de Corinto, pero también algunos otros métodos parecidos pueden verse en el modo en que gobiernan los persas. Se trata de las medidas antes mencionadas para la lograr, en la medida de lo posible, la conservación de la tiranía: degradar a los que se destaquen y asesinar a los más valientes; impedir que lleven a cabo comidas comunitarias, que se asocien, que tengan la misma educación, o cualquier cosa semejante. Se debe, además, reprimir todo aquello que estimule su coraje y su confianza; se deben abolir las escuelas y cualquiera otra forma de reunión que estimule el debate, y se debe procurar por todos los medios que no se conozcan entre sí (puesto que si se conocieran se vería reforzada su confianza) ${ }^{39}$.

37 C. Ginzburg, "Machiavelli, l'eccezione...", op. cit., p. 98.

38 Aristóteles, Política, 1310b2-b3, intr., trad. y notas de M. García Valdés, Madrid, Gredos, 1988, p. 330 con modificaciones.

39 Ibidem, p. 346 con modificaciones. 
En la traducción latina de Leonardo Bruni (que fuera republicada, como hemos visto, en 1492 en la edición comentada de Tomás de Aquino) la frase: "Se trata de las medidas antes mencionadas para la lograr, en la medida de lo posible, la conservación de la tiranía" incluía una palabra más. Un adjetivo que calificaba dichas prescripciones como perniciosa, nocivas: "Sunt autem hec illa perniciosa quae supra retulimus" ${ }^{40}$. El agregado de Bruni no parecía tener ninguna consecuencia grave. Después de todo, Aristóteles estaba presentando un elenco de medidas que evidentemente él consideraba despreciables y corruptas. Bruni lo único que había hecho era simplemente agregar una ligera pincelada para de esa manera acentuar el carácter que tenía el conjunto de la pintura. De hecho, hacia 1420, Bruni al defender su traducción de la Etica nicomaquea, comparaba a los viejos traductores de Aristóteles con aquellos pintores que desfiguraban las pinturas de Apelles, y a los buenos traductores con fieles copistas ${ }^{41}$.

¿Intentaba Bruni de esa manera evitar que las palabras de Aristóteles fueran mal interpretadas y por tanto tergiversadas? Cierto es, que en la lacónica paráfrasis del discípulo de Tomás de Aquino, Pedro de Alvernia, que Bruni debe haber conocido y que sin duda debe haber condicionado su traducción de Aristóteles en la edición romana de 1492, no podía encontrarse rastro alguno de reprobación moral. Una de las medidas que debían implementarse con el objetivo de preservar la tiranía, interpretaba el comentarista, suponía asesinar, matar (spegnere, en palabras de Maquiavelo) a los hombres más poderosos, más ricos y más sabios: "fuit excellentes in potentia vel divitiis interimere...Iterum interficere sapientes..." ${ }^{42}$. La segunda medida era algo más ambigua, puesto que suponía imitar al régimen monárquico. Decía Aristóteles:

El otro [modo de preservar el régimen tiránico] establece medidas contrarias a las hasta ahora mencionadas [...] pues así como la monarquía se corrompe cuando su poder se vuelve cada vez más tiránico, el régimen tiránico se fortalece cuando su poder se vuelve cada vez más monárquico. El tirano debe estar atento en todo momento especialmente a una cosa: debe conservar siempre la fuerza suficiente como para gobernar tanto a quienes lo apoyan como a quienes no lo hacen, en cuanto el tirano descuide este aspecto, estará renunciando a la misma tiranía [...] Ante todo, debe aparentar estar preocupado por la distribución de los recursos públicos, evitando malgastarlos en obsequios que puedan irritar al pueblo, como por ejemplo, cuando se le arrebata el producto de su trabajo y esfuerzo para dilapidarlo en prostitutas, extranjeros y artistas [...] además debe siempre aparentar un extraordinario interés en todo lo que concierne a los dioses (porque al saber que quien los gobierna es una persona devota que guarda reverencia a los dioses, los

40 Éstas son las cosas nocivas a las que nos referíamos más arriba. (Trad. F.B.). Aristoteles, Ethica, Politica et Oeconomica, Leonardo Bruni interprete, Strasbourg ante 10 abril de 1469, fol. 156v. Teniendo esto en cuenta, puedo confirmar que el término perniciosa no fue agregado por el fraile Lodovico, editor de la edición de 1492. Cf. Thomas Aquinas, Commentaria, 1492, fol. 160v.

41 C. Ginzburg, History, Rhetoric and Proof, Hanover y Londres, The University Press of New England, 1999, p. 65. El De interpretatione recta de Leonardo Bruni y las introducciones a sus traducciones han sido editadas, traducidas y comentadas por Paolo Viti. Cf. por ejemplo su edición de Leonardo Bruni, Sulla perfetta traduzione, Nápoles, Liguori, 2004. Según E. Garin ("Le traduzioni umanistiche di Aristotele", en Atti e memorie dell'Accademia fiorentina di scienze morali La Colombaria, ser. II, XVI, Florencia, Le Monnier, 1947-1950, pp. 55-104, aquí p. 67), la traducción de la Ética nicomaquea de Bruni consistió en "una reelaboración y corrección sistemática" del texto aristotélico.

42 Thomas Aquinas, Commentaria, 1492, fol. 160r-v. 
súbditos no creerán que sea capaz de ser injusto con ellos, y al mismo tiempo estarán menos predispuestos a revelarse en su contra, puesto que creerán que cuenta con la ayuda de los dioses $)^{43}$.

En ocasiones el comentario de Tomás de Aquino (es decir, de Pedro de Alvernia) sobre este inquietante pasaje suele ser leído más como una nueva versión ampliada que como un paráfrasis literal. Citaré a continuación, por ejemplo, el pasaje sobre la actitud que el tirano debe tener con respecto a la religión:

et dicit quod ad salvationem tyrannidis, tyrannus in his quae ad religionem et cultum divinum pertinent studiose et reverenter se debet habere et tanto magis differenter ab aliis quanto magis excellit. Cuius ratio est: quia subditi existiment principantem religiosum et deicolam esse non timebunt male pati ab ipso. A divino enim nullus expectat malum per se $e^{44}$.

[y dice que, para salvar la tiranía, el tirano debe mostrarse cuidadoso y respetuoso con aquellas cuestiones que conciernan a la religión y al culto divino; y debe serlo sobre todo cuanto más poderoso que los demás sea. La razón reside en que si los súbditos consideran que es fiel y religioso no temerán padecer el mal que de él provenga. Pues, por definición, de un ser divino no se puede esperar ningún mal].

Considero, por lo tanto, que merecen ser destacados tres aspectos:

(a) Para describir la actitud que los súbditos deben tener con respecto al príncipe y a su comportamiento religioso, el comentarista usa (en forma negativa) un verbo con evidentes connotaciones religiosas: timere, temer. El mismo verbo, por cierto, que había utilizado Guillermo de Moerbeke en su traducción ${ }^{45}$. Sin embargo, la glosa del comentarista - "de un ser divino (a divino) no se puede esperar ningún mal"- sugiere la fusión del poder religioso con el secular, introduciendo de esta manera un matiz ausente en el texto de Aristóteles.

(b) El comentarista transforma los actos tiránicos "contra iustitiam" (la traducción bruniana de $\tau \imath \pi \alpha \rho \alpha ́ v o \mu \nu v)$ en el sustantivo abstracto male, "el mal", dándole un carácter moral y posiblemente cristiano, al término griego vó $\mu \circ \varsigma \mathrm{y}$ a su correspondiente transgresión.

(c) Siguiendo al traductor medieval, Guillermo de Moerbeke, que había usado el término princeps, príncipe, el comentarista decide utilizar un término neutro - principans (una suerte de sinónimo de principes) - en lugar de tyrannus, $\operatorname{tirano}^{46}$.

Como podemos ver, en suma, no sería nada difícil imaginar cómo hubiera reaccionado Maquiavelo tanto ante el texto de Aristóteles (del modo en que lo había traducido Bruni) como ante su comentario.

43 [Aristóteles, Política, 1314a17 y 1315a25, pp. 351-2 y 354 (con modificaciones)]

44 Th. Aquinas, Commentaria..., op. cit., fol. 164r. (Trad. F.B.).

45 Aristotle, Politicorum libri octo..., op. cit., (n. 29), p. 581.

46 Cf., por ejemplo, Aristotle, Politica: libri I-II.11: translation prior imperfecta interprete Guillermo de Moerbeka, P. Michaud-Quantin (ed.), Brujas y París, Desclée De Brouwer, 1961, 52a30: "Principans autem natura et subiectum propter salutem" [el señor y el súbdito lo son por naturaleza en vistas al bien. (Trad. F.B.)]. Cf. el uso de principans como adjetivo en N. Rubinstein, "The History of the Word Politicus", en The Languages of Political Theory in Early-Modern Europe, A. Pagden (ed.), Cambridge, CUP, 1990, pp. 41-56. 
En repetidas ocasiones desde el siglo XVI se ha señalado el carácter maquiaveliano del quinto libro de la Política de Aristóteles. En sus Les politiques d'Aristote (1576), Louis Le Roy, profesor del Collège de France, presentaba la cuestión de un modo absolutamente explícito ${ }^{47}$. Le Roy, al comentar las acciones que implementaban los tiranos para conservar el poder, comenzaba analizando el término perniciosa, el adjetivo que había agregado Bruni en su traducción: "Et estans tres pernicieux...". También Antonio Brucioli utilizaba el mismo adjetivo en su traducción italiana de la Politica $(1547)^{48}$. Sin embargo, Le Roy no recoge las consecuencias del agregado de Bruni:

Et estans tres pernicieux [dichos métodos] n'ont été recuecillis par Aristote pour les approuver ou enseigner aux hommes ains plustot à fin de s'en garder, en cognoissant la misere des tyrans, qui sont contraincts venir à tels maux pour asseurer leurs personnes et estats. Machiavel Florentin escrivant du Prince, a tiré de ce passage la pluspart de ces instructions, en y adioustant exemples Romains et Italiens ${ }^{49}$.

[Y siendo [dichos métodos] muy nocivos, no fueron recogidos por Aristóteles ni para que los hombres los aprendieran ni para que los aprobaran, sino antes bien para prevenirlos, como buen conocedor de la miseria de los tiranos que se ven forzados a incurrir en tales males con el fin de salvaguardar tanto sus Estados como a sí mismos. El florentino Maquiavelo, al escribir sobre el príncipe, extrajo de este pasaje la mayor parte de estas enseñanzas, a las que añadió diferentes ejemplos romanos e italianos. (I.M.)].

Así Le Roy intentaba suavizar los pasajes más escandalosos de la Política de Aristóteles sugiriendo indirectamente que inclusive Il principe podía ser leído desde una perspectiva ajena al maquiavelismo. Y de esa manera, entonces, el mismo Le Roy se alejaba del estereotipo de Maquiavelo que había sido predominante durante las guerras de religión en Francia ${ }^{50}$.

Algunos críticos no parecen haber advertido la relevancia de estos matices. Se ha afirmado, por ejemplo, teniendo en cuenta que sus respectivas máximas eran, in medio stat virtus (la virtud está en el término medio), e in medio stat corruptio

47 Cf. Procacci, Machiavelli nella cultura..., op. cit., pp. 143-150.

48 Gli otto libri della republica, che chiamono Politica..., nuovamente tradotti di greco in vulgare italiano per Antonio Brucioli, Venecia (Alessandro Brucioli e fratelli), 1547, fol. 121v: "Et sono queste, quelle perniciose che io ho detto di sopra".

49 Aristotle, Les Politiques ..., esquelles est montree la science de gouverner le genre humain en toutes espèces d'estats publiques, traduittes de grec en françois, avec l'exposition des lieux les plus difficiles..., que doit considerer le politique ou le legislateur, en l'establissement d'une republique, [La Politica..., en la que se enseña la ciencia de gobernar el género humano bajo cualquier forma de Estado, traducida voluntariamente al francés, con la exposición de los supuestos más dificiles ..., que el político o el legislador debe considerar con vistas a la instauración de una república. Trad. Ignacio Massot (I.M.)] trad. de Louis Le Roy, Paris (Michel de Vascosan) 1576, p. 372.

50 L. Gentillet, Discours, sur les moyens de bien gouverner et maintenir en bonne paix un royaume ou autre principauté... Contre Nicolas Machiavel florentin, Paris o Ginebra, 1576 [Discursos sobre los modos de gobernar bien y mantener en paz un reino o algún otro principado... (I.M.)]. Cf. ahora la edición publicada en Anti-Machiavel, C. Edward Rathé (ed. y coment.), Ginebra, Librairie Droz, 1968. 
(la corrupción está en el término medio), que el aristotelismo y el maquiavelismo eran absolutamente incompatibles ${ }^{51}$. Esta convencional afirmación, basada a su vez en categorías generalizantes como aristotelismo y maquiavelismo, puede sernos de utilidad para explicar adecuadamente una cuestión que no es tan obvia como parece. Maquiavelo, quien evidentemente no era para nada reacio a los extremos, pudo haber encontrado ideas muy interesantes tanto en la Política de Aristóteles, como en los comentarios de Tomás de Aquino y de Pedro de Alvernia. De hecho, los pasajes que he citado antes, donde se describen los métodos "opuestos" que podían implementarse para preservar los regímenes tiránicos ${ }^{52}$, son más que elocuentes, si tenemos

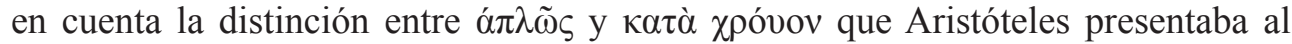
inicio de su Peri hermeneias (16a 18-19). A partir de esta obra, traducida por Boecio como De interpretatione, generaciones y generaciones de estudiantes aprendieron la diferencia entre, por un lado, una dimensión atemporal absoluta $(\dot{\alpha} \pi \lambda \tilde{\omega} \varsigma)$ y, por otro

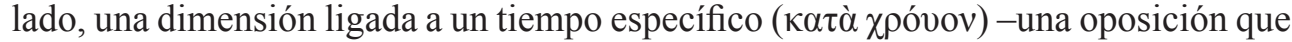
Boecio tradujo como simpliciter y secundum quid (siendo, por cierto, esta última expresión mucho más exhaustiva que la referencia aristotélica $)^{53}$. La neutral y desinteresada pregunta "¿de cuántas maneras puede impedirse la caída de un régimen tirá-

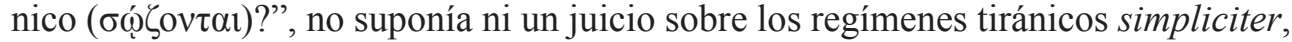
es decir, en términos absolutos, ni un determinado posicionamiento moral basado en el principio "la virtud reside en el término medio". Era un interrogante, por el contrario, que requería una respuesta ligada a unas determinadas circunstancias: una respuesta secundum quid ${ }^{5}$. Y será precisamente esta distinción crítica, presentada por Tomás de Aquino en su Summa theologiae (Secunda secundae, questio XLII), la que estimularía la posibilidad de distinguir entre conspiraciones legítimas e ilegítimas en contra de un tirano.

Maquiavelo, quien fuera encarcelado y torturado por su supuesta participación en la conspiración anti-medicea encabezada por Pietro Pagolo Boscoli, seguramente conocía bien tanto la distinción tomista, como la revisión que de esta estaban llevando a cabo los seguidores de Savonarola. De hecho, esta ya aparecía, por ejemplo, al final de la Recitazione del caso di Pietro Pagolo Boscoli e di Agostino Capponi de Luca della Robbia (escrita probablemente en 1513) ${ }^{55}$.

51 B. Guillemain, "Machiavel, lecteur d'Aristote", en Platon et Aristote à la Renaissance, XVI Colloque international de Tours: ouvrage publié avec le concours du Centre National de la Recherche Scientifique Paris. J. Vrin, 1976, pp. 163-173, esp. 169.

52 Cf. aquí nn. 39 y 43.

53 C. Ginzburg, "Mito. Distanza e menzogna" en C.G. Occhiacci di legno: nove riflessioni sulla distanza, Milano, Feltrinelli, 1998, pp. 40-81 esp. 43-48 [Cf. C. G., Ojazos de madera. Nueve reflexiones sobre la distancia, trad. cast. Alberto Clavería, Barcelona, Península, 2000, pp. 41-84].

54 Agradezco a Maria Luisa Catoni por haberme ayudado a comprender este punto.

55 Cf. Luca della Robbia, La morte di Piero Paolo Boscoli, R. Bacchelli (ed.), Florencia, Le Monnier, 1943, pp. 146-147: el fraile dominico Cipriano, del convento de San Marco, afirmó, corrigiendo su posición anterior (cf., esp. pp. 111-112): "sappi che San Tommaso fa questa distinzione: o che il tiranno i popoli sel sono addossato, o che a forza in un tratto a dispetto del popolo e' reggono. Nel primo modo non è lecito far congiura contro al tiranno, nel secondo è merito. E questo io l'ho poi letto". [debes saber que san Tomás hace esta distinción: o bien el tirano y el pueblo se encuentran obligados mutuamente, o bien el tirano gobierna decididamente por la 
Todo esto nos lleva una vez más a Scioppius, sin duda, uno de los lectores más agudos de la obra maquiaveliana. En su Paedia politices, Scioppius sostiene que tanto Aristóteles, en su Política, como Tomás de Aquino, en el comentario de dicha obra, dividían su objeto de estudio en cuatro partes ${ }^{56}$ :

(1) "la definición del mejor régimen en términos absolutos (simpliciter), y por tanto, el más deseable";

(2) "la definición del mejor régimen teniendo en cuenta determinadas circunstancias (pro conditione) [...] dado que algunos pueblos debido a su carácter no son capaces de adaptarse al mejor régimen" -como los asiáticos que, como según Plutarco afirmaba Agesilaos, son malos si viven en libertad y buenos si viven bajo la servidumbre ${ }^{57}$;

(3) el conocimiento sobre cómo reformar y mantener un determinado régimen político, tenga la forma que tenga; lo que en palabras de Aristóteles sería una "res publica ex hypothesi" (un "comunidad política hipotética"), y

(4) discernir qué tipo de régimen político "es el más difundido y el más adecuado para la mayoría del pueblo ${ }^{58}$.

"Politia est ars" ("la política es un arte"), terminaba afirmando Scioppius, que se ocupaba de una amplia gama de formas de gobierno. (Al utilizar el término ars, Scioppius recuperaba el $\tau \dot{\varepsilon} \chi v \eta$ de Aristóteles -el mismo término que estaba detrás de la fórmula maquiaveliana arte dello stato que aparece en la famosa carta a Francesco Vettori del 10 de diciembre de 1513) ${ }^{59}$. Por lo tanto, se deben analizar todos los regímenes políticos: no sólo aquel que es absolutamente el mejor (simpliciter sit optima), sino también aquel que es el mejor "teniendo en cuenta determinadas circunstancias" (pro conditione rerum), y finalmente, también, todas las demás clases de regímenes por el solo hecho de existir.

fuerza en contra del pueblo. En el primer caso no es legítimo rebelarse contra el tirano, en el segundo es de toda justicia. Y todo esto, por cierto, además yo lo he leído].

56 C. Scioppius, Paedia politices, op. cit., p. 17.

57 Plutarco, "Máximas de Espartanos", en Obras morales y de costumbres (Moralia), intr. y notas M. López Salvá y M. A. Medel, trad. M. López Salvá, Madrid, Gredos, 1987, p. 155.

58 En el ejemplar que he podido consultar en UCLA (aquí n. 4), en el punto 4 una mano del siglo XVII ha agregado una nota al margen que dice: "De tali forma Principatus agit Machiavellus". [Maquiavelo analiza esa forma de principado. (Trad. F.B.)].

$59 \quad$ En Paedia politices Scioppius le dice a lector (p. 3): “qui artem ipsam civilem sive Politicam non didicerint nec rerum civilium usum habuerunt" [quienes no aprendieron el arte civil o Política ni se implicaron en los asuntos de la comunidad. (Trad. F.B.)]. Cf. la carta del 10 de diciembre de Maquiavelo a Vettori en M., Opere, II, p. 296: "si vedrebbe che quindici anni, che io sono stato a studio all'arte dello stato, non gl'ho né dormiti né giuocati" [se podrá apreciar que los quince años que me he pasado analizando la política exterior y la política interior de Florencia no los he pasado ni durmiendo ni jugando]. Cf. R. Descendre, "Stato", en EM. II, pp. 570-576 y N.M., Epistolario privado, J. M. Forte (ed.), Madrid, La esfera de los libros, p. 211]. Sobre esta carta, cf. E. Raimondi, "Il sasso del politico", en Id., Politica e commedia. Il centauro disarmato, Bolonia, Il Mulino, 1998, pp. 3-43; J. M. Najemy, Between Friends: Discourses of Power and Desire in the Machiavelli-Vettori Letters of 1513-1515, Princeton, UP, 1993, esp. pp. 215-240 (si bien la supuestas implicaciones de las referencias maquiavelianas al relato de Getta e Birra parecen algo insuficientes) [Cf. Connell, "La carta de Maquiavelo a Vettori...", op. cit., y la bibliografía allí citada]. A cerca del arte dello stato cf. Ginzburg, "Machiavelli, l'eccezione”, op. cit., pp. 204-205 (que se basa a su vez en Singleton, "The Perspective of Art"). 
Scioppius basaba su posición en el inicio del cuarto libro de la Política de Aristóteles, leído desde el comentario que se le adjudicaba a Tomás de Aquino (que en realidad, como ya hemos señalado, había escrito Pedro de Alvernia). "El legislador y gobernante virtuoso", afirmaba Aristóteles,

no sólo debe conocer el [régimen] que es el mejor en absoluto (á $\pi \lambda \tilde{\omega} \varsigma)$, sino también el que es el mejor dadas unas determinadas circunstancias. Debe ser capaz además de discernir cómo se puede establecer un régimen a partir de determinadas condiciones previas ( el mejor régimen, sino también el mejor posible y el que pueda ser más fácilmente realizable por la mayoría de las comunidades políticas... ${ }^{60}$.

Aristóteles, por lo tanto, dejaba bien en claro que su propósito era del todo pragmático: convencer al pueblo sobre cómo debía actuar según las circunstancias que se le presentaran en cada momento:

dado que hay más complicaciones cuando se quiere reformar una constitución antigua $[\pi \mathrm{o} \lambda \imath \tau \varepsilon i ́ \alpha v]$ que cuando se pretende establecer una nueva $[\ldots]$ Y entonces, además de las virtudes del gobernante antes mencionadas, el político debe ser capaz de encontrar los remedios necesarios para los defectos de las constituciones realmente existentes, como hemos mencionado antes ${ }^{61}$.

Si mi interpretación es correcta, tanto la traducción bruniana de este pasaje como su comentario, deben haber dejado una enorme huella en el pensamiento de Maquiavelo. Veamos en primer lugar el comentario de Pedro de Alvernia:

Oportet enim qui vult corrigere aliquam policiam prius amovere inordinationes que sunt in illa policia et deinde inducere novum ordinem ${ }^{62}$.

[es necesario que quien quiera reformar una comunidad política elimine primero el desorden que hay en ella para así poder después introducir un nuevo orden].

Es posible, pues, que establecer un nuevo orden ("inducere novum ordinem"), una de las más importantes sentencias maquiavelianas ("introdurre nuovi ordini"), tenga su origen, por tanto, no en la traducción de Bruni sino en el comentario de la Política de Pedro de Alvernia atribuido a Tomás de Aquino,

Nam est non minus difficile corrigere Rempublicam iam institutam quam ab initio instituere: quemadmodum et post discere quam ab initio didicisse ${ }^{63}$.

\footnotetext{
Aristóteles, Política, op. cit., $1288 \mathrm{~b} 3$ y 1288b6, p. 216 con modificaciones.

Ibidem, 1289a7, pp. 217.

62 Th. Aquinas, Commentaria ..., op. cit., 1289a7, fol. 97r. (Trad. F.B.).

63 Ibidem. Cf. N. Machiavelli, Il Principe, op. cit., VI, 16-18 (Inglese, p. 37): “[16] Quelli e' quali per vie virtuose, simili a costoro, diventono principi, acquistano el principato con difficultà ma con facilità lo tengono; e le difficultà che gli hanno nello acquistare el principato nascono in parte da' nuovi ordini e modi che sono forzati introdurre per fondare lo stato loro e la loro sicurtà. [17] E debbesi considerare come e' non è cosa più difficile a trattare, né più dubbia a riuscire, né più pericolosa a maneggiare, che farsi capo di introdurre nuovi ordini.
} 
[Pues no es menos difícil corregir la república ya instituida que instituirla bien desde el principio, como no lo es saber más tarde lo que se debió haber sabido desde el principio].

Sin embargo, es notable cómo Bruni, una vez más, transforma la vaga mención de Aristóteles a cerca de "las virtudes del gobernante antes mencionadas" en una nueva y específica referencia a las comunidades políticas que existen solo "en los libros", "en teoría", en oposición a las que existen "realmente". Por eso mismo, pues, un ciudadano (civilis homo) debe estar dispuesto a defender ambas:

Quapropter non solum his quae libris scriptae sunt Resp[ublicae], verumetiam illis quae revera existunt auxiliari posse oportet civilem hominem ut diximus ${ }^{64}$.

[Por todo esto, como hemos señalado, conviene que el político esté capacitado no solamente para proteger e impulsar las comunidades políticas que aparecen descritas en los libros, sino también aquellas que existen efectivamente].

Maquiavelo, en una famosa sentencia de $I l$ principe (XV, 3), señalaba la oposición entre los Estados que sólo existen "en teoría" y los Estados que existen en la realidad. Sus palabras recuerdan el acento antiplatónico del pasaje de Aristóteles que acabo de citar y que él muy probablemente habría leído en la traducción de Bruni:

Ma sendo l'intenzione mia stata scrivere cosa che sia utile a chi la intende, mi è parso piú conveniente andare dreto alla verità effettuale della cosa che alla imaginazione di essa. [4] E molti si sono immaginati republiche e principati che non si sono mai visti né conosciuti in vero essere ${ }^{65}$.

[Pero dado que yo me he propuesto escribir algo que sea útil para quien pueda comprenderlo y llevarlo a cabo, he creído que era más conveniente guiarme por la verdadera realidad de la política antes que por lo que nos imaginamos que pueda ser. Puesto que muchos se han imaginado repúblicas y principados que en realidad nunca han existido].

\section{XII}

En suma, cuando Scioppius presentaba en su Paedia politices una implícita apología de algunos pensadores políticos (que nunca nombraba) que habían sido injustamente

\footnotetext{
[18] Perché lo introduttore ha per nimico tutti quegli che degli ordini vecchi fanno bene, e ha tiepidi defensori tutti quelli che delli ordini nuovi farebbono bene". [16. Aquellos que como estos llegan a ser príncipes gracias a haber llevado a cabo acciones virtuosas, tienen grandes dificultades para convertirse en príncipes, pero pueden conservar sin embargo su poder con facilidad: las dificultades que tienen para instaurar el principado están causadas en parte por las nuevas leyes e instituciones que se ven obligados a crear para erigir su poder y garantizar su seguridad. [17] No se debe olvidar nunca que no hay nada que sea más difícil de implementar, ni de más incierto resultado, ni más peligroso de controlar que dirigir la creación e instauración de nuevas leyes e instituciones. [18] Puesto que serán enemigos del autor de todas estas novedades todos aquellos que se beneficiaban del régimen anterior mientras que apenas si contará con el tímido favor de quienes podrían llegar a beneficiarse con el nuevo régimen político. Cf., N. Machiavelli, El príncipe, op. cit., p. 53]. Cf., J, H. Whitfield, “On Machiavelli's Use of Ordini", en Italian Studies X 1955, pp. 19-39 [Cf. R. Ruggiero “Ordini e Leggi”, en EM., II, pp. 251-257].

64 Th. Aquinas, Commentaria, op. cit., 1492, fol. 97r. (Trad. F.B.).

65 N. Machiavelli, Il principe, op. cit., (Inglese, p. 109).
} 
atacados, afirmaba que lo único que estos habían hecho era seguir el ejemplo de Aristóteles y de Tomás de Aquino: habían escrito ex hypothesi, es decir, siguiendo una perspectiva crítica de carácter hipotético. Por lo tanto, afirmar que un tirano, para conservar su poder, debía asesinar a hombres sabios y honorables, no constituía "un discurso definitivo, absoluto y categórico", sino uno hipotético que solo podía entenderse a partir de tener en cuenta unas determinadas y específicas circunstancias ${ }^{66}$. De hecho, este ejemplo, tomado de Aristóteles y de su comentarista, era introducido por una afirmación de carácter aún más general. Algunos suelen criticar, observaba Scioppius, que quienes escriben sobre política se limiten simplemente a describir los regímenes tiránicos sin decir ni un palabra sobre cuán nefastos son. Sin embargo, en realidad, un verdadero filósofo sabe muy bien que tales juicios "no pertenecen en absoluto al campo de la reflexión política (schola politica): pertenecen al ámbito de la ética y de la filosofía moral ${ }^{67}$. (Tres siglos después de que Scioppius publicara su Paedia politices, y sin citarla, Benedetto Croce consideraba como algo "evidente" que Maquiavelo había descubierto "l'autonomia della política") ${ }^{68}$.

Pero en cualquier caso Scioppius había presentado también otro argumento muy diferente en defensa de Maquiavelo. Una explicación podía ser "directa y fácilmente comprensible o bien oblicua y oscura". Si un político (es decir, Maquiavelo) afirmaba, entre otras cosas, "que un tirano es mitad hombre y mitad animal, parte león y parte zorro", uno podría llegar a la conclusión entonces, observaba Scioppius, que se debía hacer todo lo posible, precisamente, para evitar el surgimiento de regímenes tiránicos ${ }^{69}$.

A pesar de que hoy nadie aceptaría una interpretación tan simplista, la imagen de $\mathrm{Il}$ principe como un texto de carácter anti-tiránico -sugerida, si bien indirectamente, como veíamos antes, por Louis Le Roy- ha llegado a tener, sin embargo, bastante éxito. Ahora bien, ¿hasta qué punto podríamos aceptar la posición menos convencional de Scioppius según la cual Maquiavelo escribió ex hypothesi, desde una perspectiva hipotética?

\section{XIII}

En el contexto de la argumentación que he presentado aquí, el término "perspectiva" no debería ser entendido como una mera metáfora. En la dedicatoria de Il principe a Lorenzo de 'Medici il giovane (más tarde, Duque de Urbino), Maquiavelo se compara a sí mismo con un pintor de paisajes, "come coloro che disegnano e paesi". Probablemente esta fuera una referencia al famoso mapa de Leonardo da Vinci que reproducía la vista aérea de la ciudad de Imola. Como se recordará, Leonardo y Ma-

66 C. Scioppius, Paedia politices, op. cit., p. 30: "est loquendi modus non absolutus, simplex, aut categoricus sed hypotheticus, sive cum exceptione aut conditione".

${ }^{67}$ Ibidem, p. 20: "Hoc autem a schola politica alienissimum esse, et ad ethicam vel moralem pertinere".

68 B. Croce, Elementi di politica [1924], en su Etica e politica, Bari, Laterza, 1931, p. 251: "Ed è risaputo che Machiavelli scopre la necessità e l'autonomia della politica, della politica che è di là, o piuttosto di qua, dal bene e dal male morale...." [Y es bien sabido que Maquiavelo descubre la necesidad y la autonomía de la política, de la política que está más allá, o sobre todo más acá, del bien o del mal moral...”]. Cf. J. H. Whitfield, "The Politics of Machiavelli”, en The Modern Language Review I, 1955, pp. 433-443, esp. 433.

69 C. Scioppius, Paedia politices, op. cit., pp. 30-31: "vel directa et apertior, vel obliqua et occultior [...] Si ergo dicat Politicus, Tyrannum esse semi-hominem et semi-belluam, ex leone puta et vulpe compositum". 
quiavelo se habían conocido en Imola en 1503, en la corte de Cesare Borgia ${ }^{70}$. Decía Maquiavelo en Il principe, dedica, 5:

Né voglio sia imputata prosunzione se uno uomo di basso e infimo stato ardisce discorrere e regolare e' governi de' principi; perché cosi come coloro che disegnano e' paesi si pongono bassi nel plano a considerare la natura de' monti e de' luoghi alti e, per considerare quella de 'luoghi bassi, si pongono alto sopr 'a'monti, similmente, a conoscere bene la natura de' populi bisogna essere principe e a conoscere bene quella de' principi conviene essere populare ${ }^{71}$.

[Tampoco quisiera que se acusara de soberbia a un hombre de baja condición social que se atreve a analizar y juzgar cómo gobiernan los príncipes. Porque de la misma manera que aquellos que pintan paisajes se ubican allí abajo en la llanura para poder así observar mejor la naturaleza de los montes y de los lugares más elevados y, cuando tienen que observar los lugares más bajos, se ubican en lo alto de los montes, de la misma manera, para conocer mejor la naturaleza de los súbditos, es necesario ser príncipe y para conocer la naturaleza del príncipe, es necesario ser parte de los súbditos].

La aparición de la perspectiva lineal proporcionó a Maquiavelo una poderosa metáfora -un equivalente cognitivo- de su propio enfoque crítico sobre la política, en el que interactuaban tanto el secundum quid y como el simpliciter. Solo y únicamente partiendo de un punto de vista determinado y contextualizado era posible acceder a la verità effettuale della cosa. Un descubrimiento decisivo, cuyas consecuencias, para bien o para mal, aun hoy conviven entre nosotros.

70 C. Ginzburg, "Distanza e prospettiva. Due metafore", en C.G. Occhiacci di legno, op. cit., [trad. cast. pp. 183205]. [Cf. R. Descendre, "Leonardo da Vinci", en EM. II, pp. 61-64].

71 N. Machiavelli, Il principe, op. cit., (Inglese), p. 6. [Cf. N.M., El príncipe..., pp. 5-7]. 